\title{
Effect of Sulphuric Acid Concentration on Anodised Titanium for Biomedical Application
}

\author{
M.A. Selimin, Z. Malik, N. Anjang, M.I. Idris, and H.Z. Abdullah
}

\begin{abstract}
Anodic oxidation (AO) is a chemically electrode reactions between electric field driven metal and oxygen ion diffusion to the formation of an oxide film on anode surface. This method able to modified the oxide layer of titanium (Ti) from smooth (bioinert) to porous surface (bioactive) by thickening the oxide film which enhance osseointegration and corrosion resistance of the Ti. This paper presents a study of surface characterisations of anodised titanium in sulphuric acid $\left(\mathrm{H}_{2} \mathrm{SO}_{4}\right)$ formed via anodic oxidation. Anodic films were obtained by using AO method in sulphuric acid, where the concentration and voltage were varied in the range of 0.3-1.8 M and 50-200 $\mathrm{V}$ respectively. The samples are examined by using $\mathrm{X}$-ray diffractometer (XRD), field emission scanning electron microscopy (FESEM) and atomic force microscopy (AFM). From XRD analysis, oxide conversion is identified from very small amount of anatase $(50 \mathrm{~V})$ to high crystallinity of anatase at $100 \mathrm{~V}$ and mixture of anatase and rutile at $200 \mathrm{~V}$. The FESEM results show that the surface of titanium changed from smooth to rough surface by increasing the applied voltage and concentration of electrolyte. The surface roughness (Ra) of anodic titanium increased with increment of the voltage and concentration of sulphuric acid.
\end{abstract}

Keywords-Anodic oxidation, titanium, biomaterials, thin film, sulphuric acid

\section{Introduction}

Titanium has been used in biomedical since 50 years ago because of possess desirable properties such as excellent mechanical properties, lightweight, high corrosion resistance and biocompatibility with living tissue after implantation into human bone [1]. There many medical devices and artificial implants were made using titanium such as artificial hip-joint implant, dental parts, stents, artificial heart valve and many more [2].

Basically, there are four types of biomaterials with classified according to tissue response; toxic, bioinert, bioactive and bioresorble [3]. Due to several advantages of titanium properties compared to other materials, being bioinert metallic materials, it cannot bond to living bone directly when implanted inside living body [4]. Therefore, various methods were purposed to enhance and overcome this major problem of the titanium so that it will improve the interlocking ability and biological activity (tissue biocompatibility) of the titanium when implanted as implant [5].

Hasan Zuhudi Abdullah

Universiti Tun Hussein Onn Malaysia

Malaysia
Surface modification method will modifying the oxide layer of the titanium by producing bioactive $\mathrm{TiO}_{2}$ layer where it was known that there are three types of polymorphs of titanium; anatase, rutile and brookite [6]. As like any other metallic materials, thin passivation oxide layer of titanium $(10-15 \mathrm{~nm})$ on the surface can be formed naturally by exposing titanium to the air [7]. Among the three polymorphs of titanium, anatase is the most suitable form of photocatalytic activity while brookite normally difficult to obtain during the ceramic processing [8]. Rutile is the stable form of titanium oxide at ambient conditions which possesses unique semiconductor characteristics [9]. The crystalline oxides (anatase and rutile) present several unusual features such as good photocatalytic behavior, superhydrophilicity and biocompatible [10]. Several studies were done and proved that anatase and/or rutile $\mathrm{TiO}_{2}$ crystallinity (porous surface) showed excellent apatite precipitation ability and able to produced compact apatite layer on titanium sample in very short times after soaked in simulated body fluid (SBF) to study the bioactivity properties of anodic titanium film [11].

There are many types of surface modification techniques can be applied to titanium to produce bioactive titanium oxide layer (titania or $\mathrm{TiO}_{2}$ ) such as chemical treatment, solgel, chemical vapour deposition, thermal spray, ion implantation and deposition, anodic oxidation and many more [12]. Recently, anodic oxidation has proven useful for producing titanium oxide $\left(\mathrm{TiO}_{2}\right)$ coating on titanium substrate and able to enhance the bone conductivity and interlocking implant to bone [13]. Anodic oxidation encompassed electrode reactions in combination of electric field metal driven and oxygen ion diffusion to the formation of an oxide film on anode surface. Anodic oxidation technique also allows controlling the formation of oxide layer which is thicker than formed naturally [14].

It was reported that by applying a positive voltage to a $\mathrm{Ti}$ specimen immersed in an electrolyte, anodic oxidation of titanium occurs to form a $\mathrm{TiO}_{2}$ layer on the surface. When the applied voltage is increased to a certain point, a microarc sparkling occurs as result of the dielectric breakdown of the $\mathrm{TiO}_{2}$ layer. At this point, local heating occurs on the specimen and raised the temperature during anodic oxidation makes the rutile $\mathrm{TiO}_{2}$ becomes more stable than anatase $\mathrm{TiO}_{2}$ at high temperature [15].

This paper presents work on modification of oxide surface of titanium by anodising the commercially high purity titanium (Ti) in different concentration of electrolyte of sulphuric acid. The applied voltage also varied to investigate the effect of conditioning parameters in order to produce bioactive titanium for biomedical application. The oxide surface will be evaluated by using XRD, FESEM and AFM. 


\section{Experimental Method}

\section{A. Sample Preparation}

High purity of titanium foils with dimension $25 \mathrm{~mm} \times 10$ $\mathrm{mm}$ and a thickness of $0.05 \mathrm{~mm}$ were used as substrates. The surfaces of the samples were wet and polished using 1200 grit $(\sim 1 \mu \mathrm{m})$ silicon carbide (SiC) abrasive paper to remove native layer of the sample, followed by cleaning and rinsed with acetone and distilled water, and drying using compressed air.

\section{B. Anodic Oxidation}

Anodic oxidation was done by using programmable power supply (Genesys 600-1.3, Densai-Lambda, Japan) in electrochemical cell containing $400 \mathrm{ml}$ acidic solutions of sulphuric acid $\left(\mathrm{H}_{2} \mathrm{SO}_{4}\right)$ at room temperature. The anode and cathode were titanium films and the experimental parameters used are shown in Table I. The anodised titanium was cleaned by dipping in distilled water, followed by drying in still air. Figure 1 shows the schematic apparatus setup of anodic oxidation [16].

TABLE I. PARAMETERS USED FOR ANODIC OXIDATION

\begin{tabular}{||l|c||}
\hline \multicolumn{1}{|c|}{ Parameter } & Value (s) \\
\hline \hline Electrolytes & Sulphuric acid $\left(\mathrm{H}_{2} \mathrm{SO}_{4}\right)$ \\
\hline Concentration $(\mathrm{M})$ & $0.3,0.9,1.8$ \\
\hline d.c voltage $(\mathrm{V})$ & $50,100,200$ \\
\hline Current density $\left.\left(\mathrm{mA}_{\mathrm{A}}\right) \mathrm{cm}^{-2}\right)$ & 75 \\
\hline Duration $(\min )$ & 10 \\
\hline
\end{tabular}

\section{Sample Characterisations}

The mineralogical composition of the films was determined using X-ray diffractometer (XRD; X'Pert ${ }^{3}$ Powder, PANalytical, Netherlands) at $40 \mathrm{kV}$ and $40 \mathrm{~mA}$, angle of incidence of $1^{\circ}$, scanning speed of $0.067 \%$. The microstructures were examined by using field emission scanning electron microscopy (FESEM; JSM-7600F, Joel

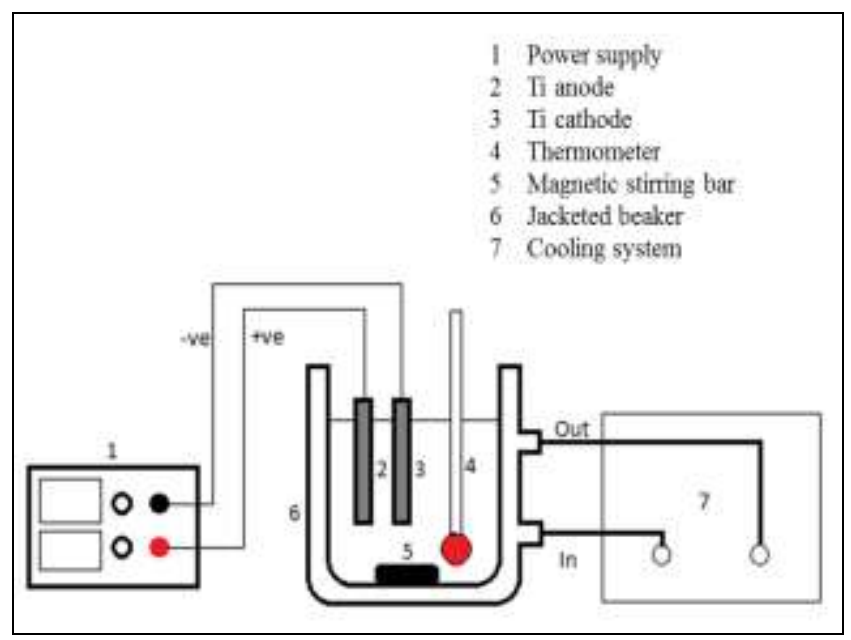

Figure 1. Schematic apparatus setup of anodic oxidation [16].
Ltd., Japan) at an accelerating voltage of $5 \mathrm{kV}$. The surface profile was determined by using atomic force microscopy (AFM; XE-100, Park System, South Korea) with $10 \mu \mathrm{m}$ scanning size, $250-850 \mathrm{~nm}$ wavelength, non-contact measurement mode and $3 \mathrm{~mm}$ distance between cantilever and sample.

\section{Results \& Discussion}

\section{A. Mineralogical of Samples}

Figure 2, Figure 3 and Figure 4 show the XRD patterns of the anodic titanium films under different applied voltage and concentration of electrolyte at current density of 75 $\mathrm{mA} \cdot \mathrm{cm}^{-2}$ at $10 \mathrm{~min}$ anodisation time. Every different concentration of electrolyte show that same trend of oxide formation which is at $50 \mathrm{~V}$, very small amount anatase was formed on the titanium surface leads to small peak detected on XRD results. This happened due to combination of electric field driven of titanium and oxygen ion diffusion is not strong enough to breakdown the dielectric layer to produce more anatase $\mathrm{TiO}_{2}$ on the sample surface. The results indicated that the amount of anatase and rutile increased with increasing of applied voltage and concentration of electrolyte. It is clear that the concentration of electrolyte affect the formation of crystalline of oxide layer by increased the value applied.

From the same figures, it shows that high crystallinity of anatase can be obtained at $100 \mathrm{~V}$ of each electrolyte concentration. High crystalline of anatase is very important for titanium to be used as bioactive material because this phase is more effective in apatite formation in simulated body fluid [17]. At $100 \mathrm{~V}$, the XRD patterns show that the anatase $\mathrm{TiO}_{2}$ more stable than rutile $\mathrm{TiO}_{2}$ where only small amount of rutile was detected in this sample with concentration $0.9 \mathrm{M}$ and $1.8 \mathrm{M}$. These results also indicated that the high concentration of sulphuric acid $(1.8 \mathrm{M})$ formed high crystalline of anatase compared to others $(<1.8 \mathrm{M})$. Apart from that, mixture of anatase and rutile were observed at higher voltage $(200 \mathrm{~V})$. It was known that higher concentration of electrolyte and applied voltage resulted localised heating and raised the temperature of the system during anodic oxidation [18]. At this stage, rutile became more stable than anatase which leads to formation more rutile crystalline than anatase $\mathrm{TiO}_{2}$. There are different amount and movement of bubbles on anode surface during anodic oxidation. It can be conclude that the more and active movement of bubbles formed on the anode surface, the formation of high crystallinity of anatase and rutile can be obtained. The localised heating on anode leads to occurring of micro-arc sparkling resulted formation more rutile $\mathrm{TiO}_{2}$ than anatase.

The results also showed that different parameter of anodic oxidation will leads to differ formation of oxide layer. It is because different parameter will produce different corrosiveness potential that able the process to reach dielectric breakdown which able to produce porous surface on the titanium. It was known that the oxygen ion $\left(\mathrm{O}_{2}\right)$ from the electrolyte will migrate into the titanium interface and leads to migration of $\mathrm{Ti}^{4+}$ ions from the titanium substrate to the film/electrolyte interface [19]. The summary of XRD analysis was tabulated in Table II. 
Proc. of the Third Intl. Conf. Advances in Civil, Structural and Mechanical Engineering- CSM 2015 Copyright (C) Institute of Research Engineers and Doctors, USA .All rights reserved.

ISBN: 978-1-63248-062-0 doi: 10.15224/ 978-1-63248-062-0-36

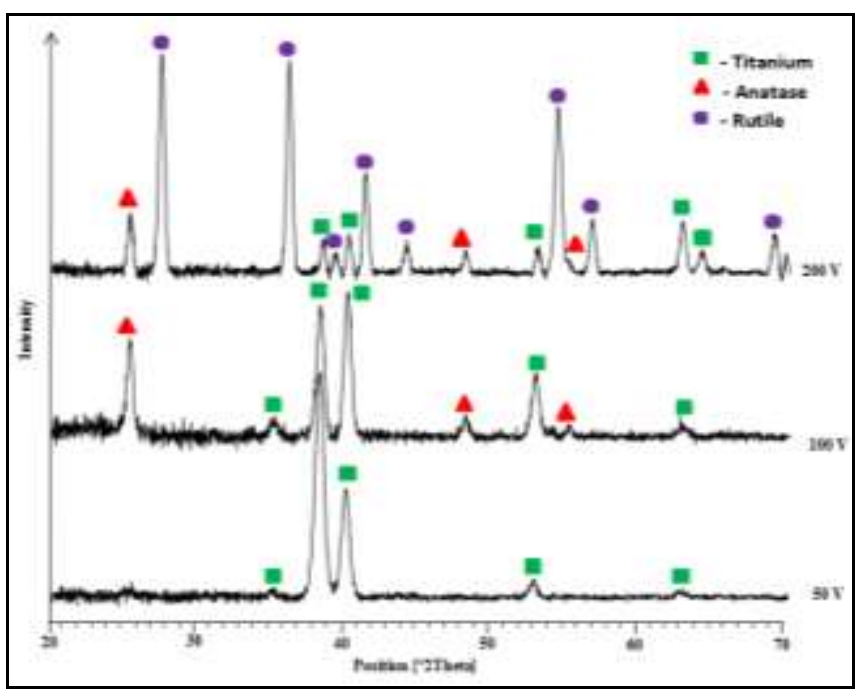

Figure 2. XRD analysis of anodised samples at $75 \mathrm{~mA} \cdot \mathrm{cm}^{-2}$ in $0.3 \mathrm{M}$ of $\mathrm{H}_{2} \mathrm{SO}_{4}$.

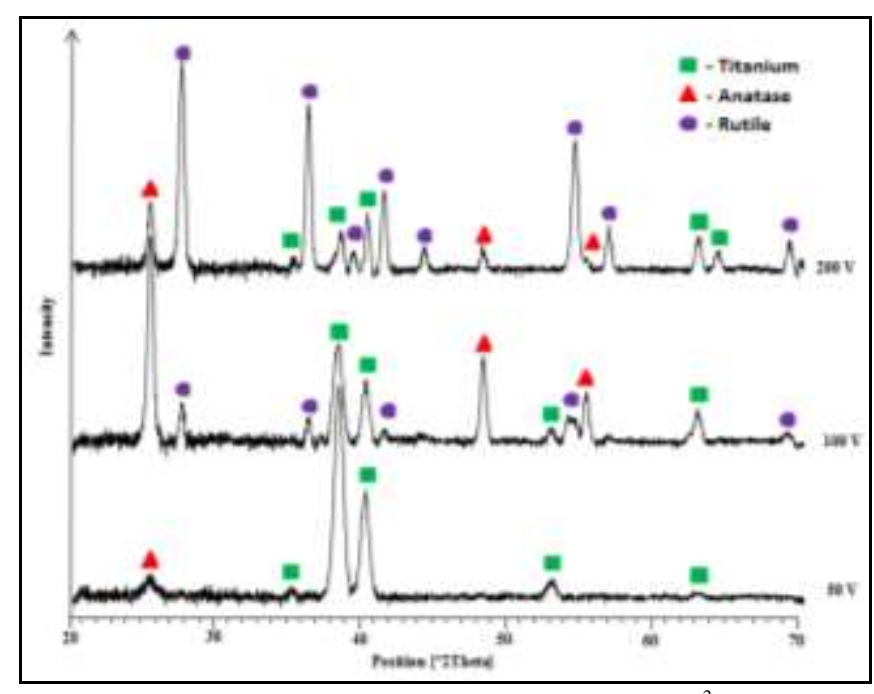

Figure 3. XRD analysis of anodised samples at $75 \mathrm{~mA} . \mathrm{cm}^{-2}$ in $0.9 \mathrm{M}$ of $\mathrm{H}_{2} \mathrm{SO}_{4}$.

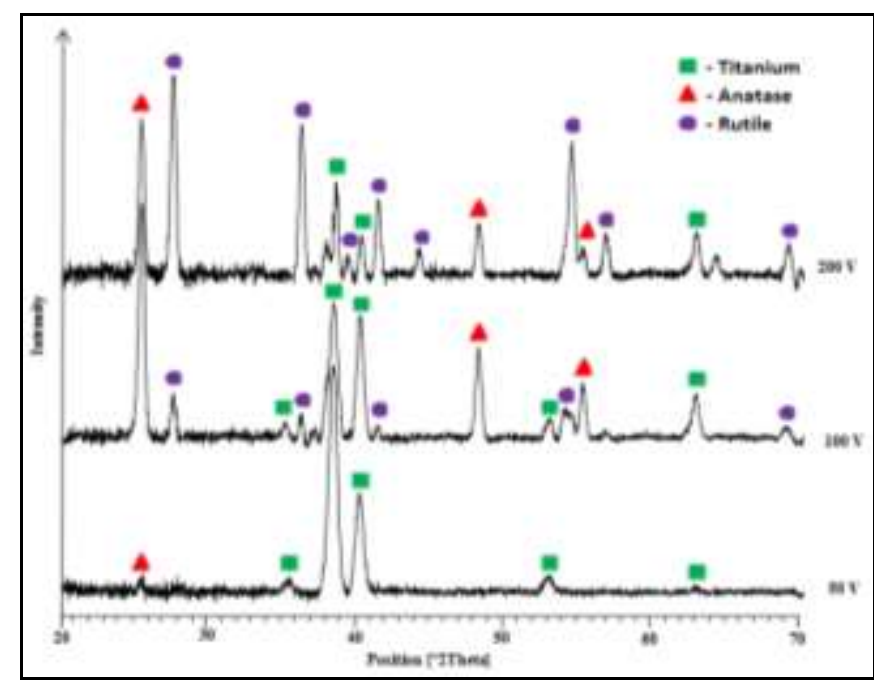

Figure 4. XRD analysis of anodised samples at $75 \mathrm{~mA} . \mathrm{cm}^{-2}$ in $1.8 \mathrm{M}$ of $\mathrm{H}_{2} \mathrm{SO}_{4}$.
TABLE II. SUMMARY OF XRD ANALYSIS

\begin{tabular}{|c|c|c|c|}
\hline \multirow{2}{*}{$\begin{array}{c}\text { Voltage } \\
\text { (V) }\end{array}$} & \multicolumn{3}{|c|}{ Concentration of electrolyte (M) } \\
\cline { 2 - 4 } & $\mathbf{0 . 3}$ & $\mathbf{0 . 9}$ & $\mathbf{1 . 8}$ \\
\hline \hline $\mathbf{5 0}$ & $\begin{array}{c}\text { No anatase or } \\
\text { rutile }\end{array}$ & $\begin{array}{c}\text { Very low } \\
\text { crystalline of } \\
\text { anatase }\end{array}$ & $\begin{array}{c}\text { Very low } \\
\text { crystalline of } \\
\text { anatase }\end{array}$ \\
\hline $\mathbf{1 0 0}$ & $\begin{array}{c}\text { High crystalline } \\
\text { of anatase }\end{array}$ & $\begin{array}{c}\text { High crystalline } \\
\text { of anatase than } \\
\text { rutile }\end{array}$ & $\begin{array}{c}\text { High crystalline } \\
\text { of anatase than } \\
\text { rutile }\end{array}$ \\
\hline $\mathbf{2 0 0}$ & $\begin{array}{c}\text { High crystalline } \\
\text { of rutile than } \\
\text { anatase }\end{array}$ & $\begin{array}{c}\text { High crystalline } \\
\text { of rutile than } \\
\text { anatase }\end{array}$ & $\begin{array}{c}\text { High crystalline } \\
\text { of rutile than } \\
\text { anatase }\end{array}$ \\
\hline \hline
\end{tabular}

\section{B. Surface Morphological of Samples}

Figure 5 displays the surface morphologies of the anodic films obtained from oxidation process in different concentration of electrolyte and applied voltage observed by FESEM. At $50 \mathrm{~V}$, the FESEM micrographs show almost same images for different electrolyte concentration where craters (coffee bean shape) were formed on titanium surface. These also indicated that at this voltage is the onset of anodising effect where the changes of smooth surface to some crater on the surface of the titanium observed. While at $100 \mathrm{~V}$, the trend shows that at low electrolyte concentration $(0.3 \mathrm{M})$ there is some small open pores are clearly seen on the sample. The pore size became bigger with increment of electrolyte concentration up to $1.8 \mathrm{M}$ and more pores covered the surface of the titanium. At $200 \mathrm{~V}$, the surface images are almost same for differ electrolyte concentration where three-dimensional oxide structure was formed except the size of pores and boundaries became bigger and thin respectively with increment of electrolyte concentration. By referring to XRD and FESEM results, the formation of three-dimensional structure occurred when rutile $\mathrm{TiO}_{2}$ was formed on the sample.

\section{Surface Profile of Samples}

Figure 6 shows that the oxide formed on the titanium surfaces are changed with increasing the applied voltage and concentration of electrolyte. At $50 \mathrm{~V}$ there are numerous small and sharp oxides formed on the titanium surface and the polishing effect is invisible on this sample. These oxides changed to big oxide at $100 \mathrm{~V}$ due to some pores are formed on the titanium surface. There is also black spot observed on the AFM images which belong to pores formed on the titanium surface. This black spot became bigger at $200 \mathrm{~V}$ because when referring to FESEM results, the pores size and boundaries increased and decreased respectively with increment of electrolyte concentration.

In Figure 6, the surface roughness (Ra) of anodic titanium shows increment trend by increasing the applied voltage and concentration of electrolyte. The surface roughness values indicated that the higher the voltage and concentration of sulphuric acid, the rougher or porous the titanium specimen can became. This happened due to different concentration of electrolyte has different oxygen ion diffusion potential (ionise potential), which able to break the dielectric layer at high electrolyte concentration and voltage. 
Proc. of the Third Intl. Conf. Advances in Civil, Structural and Mechanical Engineering- CSM 2015 Copyright (@) Institute of Research Engineers and Doctors, USA .All rights reserved.

ISBN: 978-1-63248-062-0 doi: 10.15224/ 978-1-63248-062-0-36

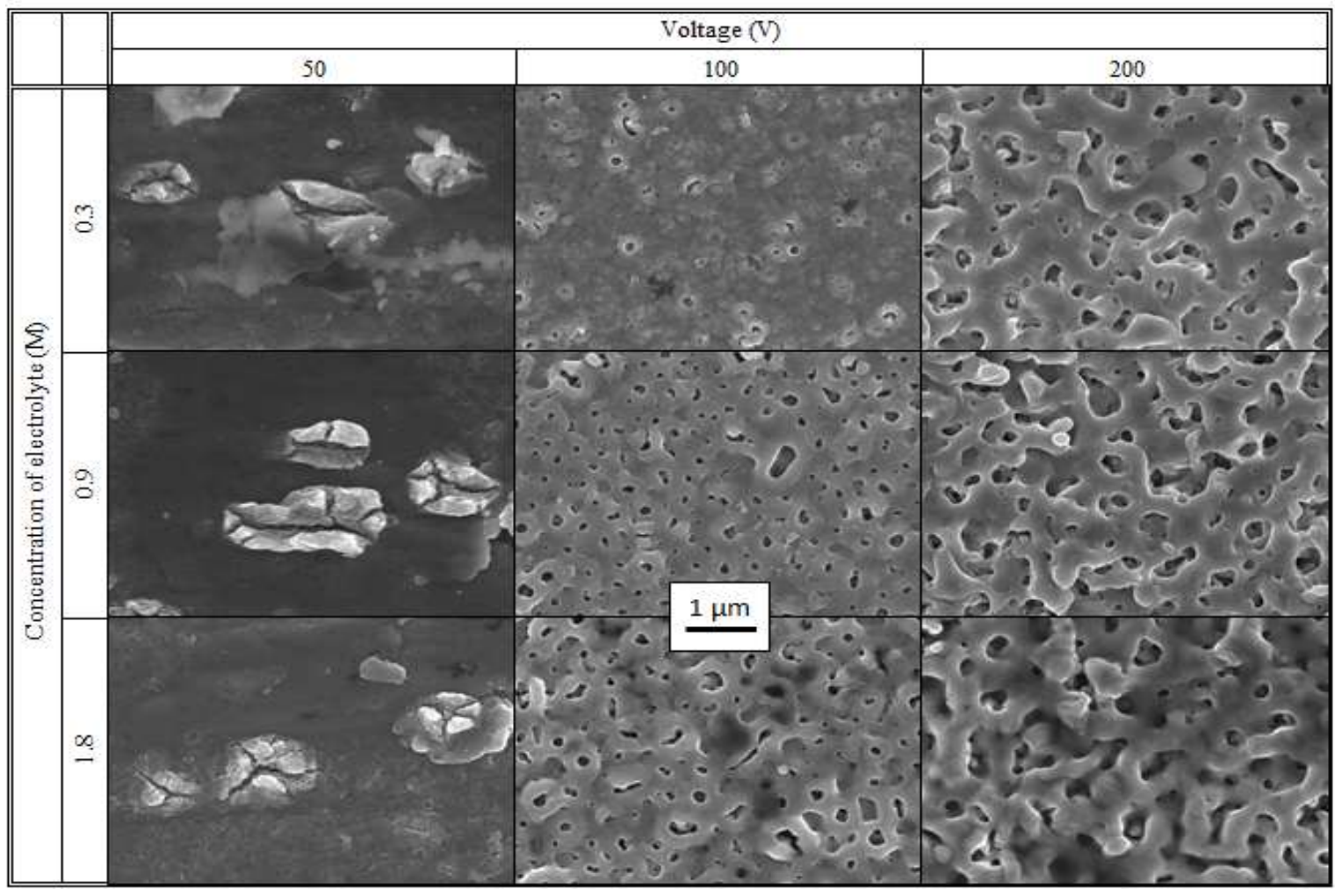

Figure 5. FESEM micrographs of anodised titanium in $\mathrm{H}_{2} \mathrm{SO}_{4}$ at $75 \mathrm{~mA} . \mathrm{cm}^{-2}$.

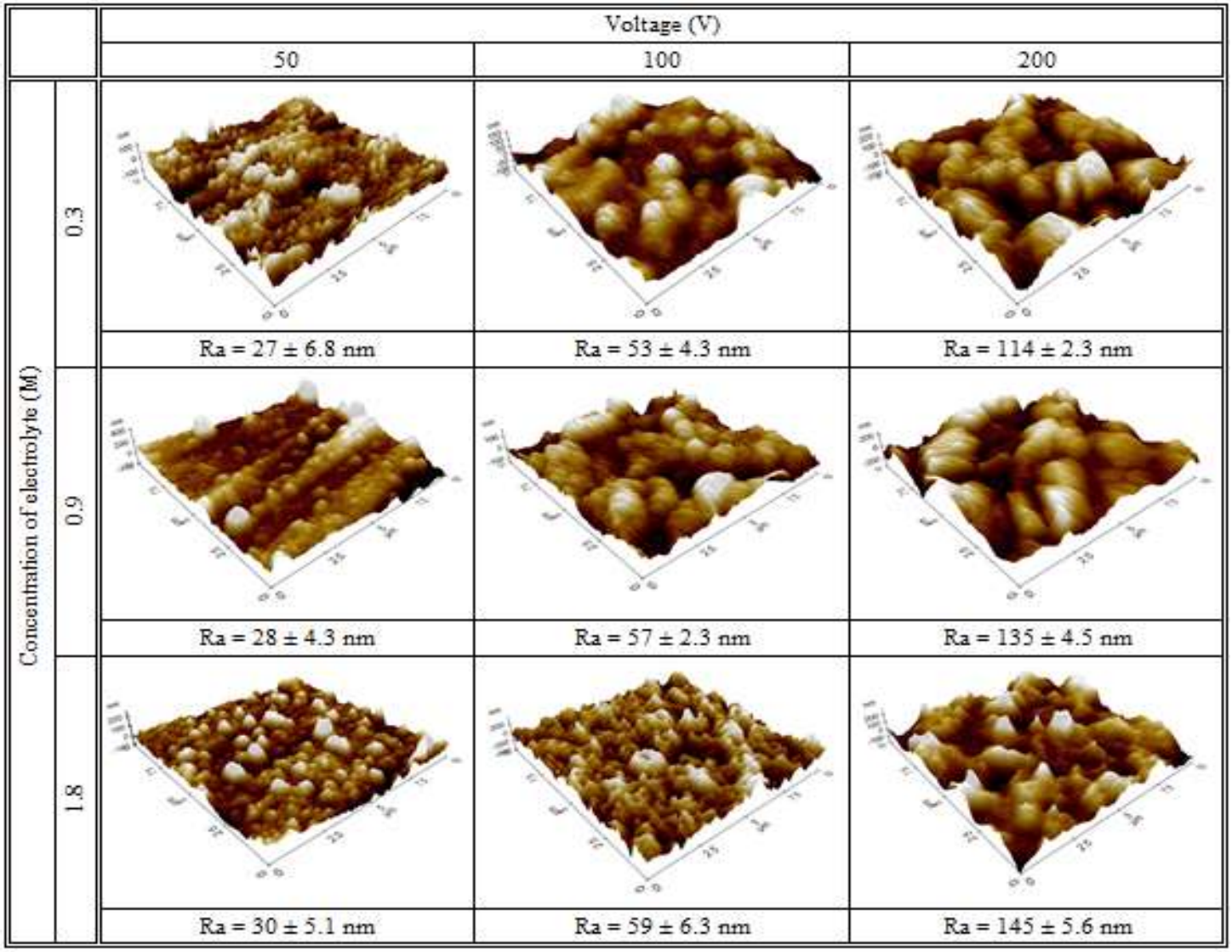

Figure 6. AFM images of anodised titanium in $\mathrm{H}_{2} \mathrm{SO}_{4}$ at $75 \mathrm{~mA} . \mathrm{cm}^{-2}$. 


\section{Conclusions}

After anodic oxidation in $\mathrm{H}_{2} \mathrm{SO}_{4}$ aqueous solution, porous $\mathrm{TiO}_{2}$ layers mainly consisted of anatase and/or rutile phases produced on the surface of the titanium. It is found that a simple and effective technique can be used to produce bioactive titanium via anodic oxidation in $\mathrm{H}_{2} \mathrm{SO}_{4}$ solution. In this study, high crystallinity of anatase can be obtained by using $100 \mathrm{~V}$ of applied voltage in $1.8 \mathrm{M}$ of $\mathrm{H}_{2} \mathrm{SO}_{4}$ without performing an additional post treatment after anodic oxidation for conversion of amorphous oxide. There is also formation of mixture between anatase and rutile on the titanium surface where local heating was occurred during anodic oxidation process which leads to micro-arc sparkling. It was known that anatase and/or rutile crystalline played an important role in inducing the apatite growth because of the relationship of lattice matching between this crystalline and apatite. The surface morphology, mineralogy, surface roughness and surface profile of Ti films were strongly affected by the applied voltage and concentration of electrolyte to meet clinical in order to enhance the interlocking implant to bone when implanted inside human body.

\section{Acknowledgment}

The author would like to acknowledge the support of Ministry of Higher Education of Malaysia (MOHE) for funding the current research grant, FRGS Vot 1419 and FRGS Vot 1212 for performing this work. All those who contributed directly or indirectly are thanked.

\section{References}

[1] E. Santos, N.K. Kuromoto, and G.A. Soares, "Mechanical properties of titania films used as biomaterials", Materials, Chemical \& Physicals, vol. 102, pp. 92-97, 2007.

[2] T. Kizuki, H. Takadama, T. Matsushita, T. Nakamura, and T. Kokubo, "Preparation of bioactive Ti metal surface enriched with calcium ions by chemical treatment”, Acta Biomaterialia, vol. 6, pp. 2836-2842, 2010.

[3] L.L. Hench, "Bioceramics", Journal of American Ceramic Society, vol. 81, pp. 1705-1728, 1998 .

[4] X. Cui, H.M. Kim, M. Kawashita, L. Wang, T. Xiong, T. Kokubo, and T. Nakamura, "Preparation of bioactive titanium films on titanium metal via anodic oxidation", Dental Materials, vol. 25, pp. 80-86, 2009.

[5] K.J. Tan, H.Z. Abdullah, M.I. Idris, and C.C. Sorrell, "Gel oxidation of titanium at low concentration of sodium hydroxide $(\mathrm{NaOH})$ ", Advanced Materials Research, vol. 1087, pp. 340-344, 2015.

[6] W. Payakgul, O. Mekasuwandumrong, V. Pavarajarna, and P Praserthdama, "Effect of reaction medium on the synthesis of $\mathrm{TiO}_{2}$ nanocrystals by thermal decomposition of titanium (IV) n-butoxide:", Ceramics International, vol. 31, pp. 391-397, 2005

[7] M. Keshmiri and T. Troczynski, "Apatite formation on $\mathrm{TiO}_{2}$ anatase microspheres", Non-Crystalline Solids, vol. 324, pp. 289-294, 2003.

[8] A. Ravaglioli and A. Krajewski, "Bioceramics: Materials, Properties, Application", Chapman \& Hall, London, 1992.

[9] H. Wu, X. Lu, B. Long, X. Wang, J. Wang, and Z. Jin, "The effect of cathodic and anodic voltages on the characteristics of porous nanocrystalline titania coatings fabricated by micro arc oxidation:", Materials Letters,vol. 59, pp. 370-375, 2005.

[10] M.V. Diamanti and M.P. Pedeferri, "Effect of oxidation parameters on the titanium oxides formation", Corrosion Science, vol. 29, pp. 939-948, 2007.

[11] H.J. Song, S.H. Park, S.H. Jeong, and Y.J. Park, "Sruface characteristics and bioactivity of oxide films formed by anodic spark oxidation on titanium in different electrolytes", Materials Processing Technology, vol. 209, pp. 864-870, 2009.

[12] X. Liu, P.K. Chu, and C. Ding, "Surface modification of titanium, titanium alloys, and related materials for biomedical applications", Materials Science \& Engineering R., vol 47, pp. 49-121, 2004.

[13] M.A. Selimin, N.H.M. Idrus, and H.Z. Abdullah, "Anodic oxidation of titanium for biomedical application", Advanced Materials Research, vol. 1087, pp. 81-85, 2015.

[14] N.K. Kuromot, R.A. Simao, and G.A. Soares, "Titanium oxide films produced on commercially pure titanium by anodic oxidation with different voltage", Materials Characterization, vol. 58, pp. 114-121, 2007.

[15] Y. Han, S.H. Hong, and K. Xu, "Structure and in vitro bioactivity of titania-based films by micro-arc oxidation", Surface Coatings Technology, vol. 168, pp. 249-258, 2003.

[16] H.Z. Abdullah, P. Koshy, and C.C. Sorrell, "Anodic oxidation of titanium in mixture of $\beta$-glycerophosphate ( $\beta$-GP) and calcium acetate (CA)", Key Engineering Materials, vol 275, pp. 594-595, 2014.

[17] T.C. Lee, M.I. Idris, H.Z. Abdullah, and C.C. Sorrell, "Effect of current density on anodised titanium in mixture $\beta$-Glycerophosphate ( $\beta$-GP) and Calcium Acetate (CA)", Advanced Materials Research, vol. 1087, pp. 212-217, 2015.

[18] L.H. Li, Y.M. Kong, H.W. Kim, Y.W. Kim, H.E. Kim, S.J. Heo, and J.Y. Koak, "Improved biological performance of Ti implants due to surface modification by micro-arc oxidation", Biomaterials, vol. 25, pp. 2867-2875, 2004.

[19] T.C. Lee, M.I. Idris, H.Z. Abdullah, and C.C. Sorrell, "Effect of electrolyte concentration on anodised titanium in mixture $\beta$ Glycerophosphate ( $\beta-\mathrm{GP})$ and Calcium Acetate (CA)", Advanced Materials Research, vol. 1087, pp. 116-120, 2015. 